\title{
ASSESSMENT OF THE GOVERNANCE PRACTICES IN PUBLIC SECTOR: CASE STUDIES OF MALAYSIAN FEDERAL GOVERNMENT AGENCIES
}

\author{
Siti Zabedah Saidin',", Mu'azu Saidu Badara², and Aidi Ahmi' \\ ${ }^{1}$ Tunku Puteri Intan Safinaz School of Accountancy, Universiti Utara Malaysia, Malaysia \\ ${ }^{3}$ Department of Business Administration, Ahmadu Bello University, Zaria, Nigeria
}

\begin{abstract}
The objective of this study is to discover the good governance practices in the public sector entities by assessing ten good governance dimensions following the international best governance practices guidelines. This study is based on a case study analysis of six public sector entities using a content analysis of the annual report. From the case studies analysis, it shows that all the dimensions in the international public sector governance best practices are being practiced by the federal statutory bodies in Malaysia. Though this paper provides some useful insights into governance practices among public sector entities, it is limited to case studies on six federal statutory bodies and the non-financial information in the annual reports only. This study might give more impact if primary data were used through focus group discussions and interviews with key governance players in the public sector.
\end{abstract}

ARTICLE HISTORY

Received: 15-01-2019

Accepted: 10-04-2019

\section{KEYWORDS}

Public sector governance, governance practice, public sector, Federal government agencies

\section{INTRODUCTION}

Most of the developed nations have shown their concern over the realisation of good governance within their public sector. Effective governance in the public sector stimulates quality decision making, warrants the efficient use of resources and reinforces the accountability for the stewardship of those resources, ensure the improvement of public sector performance and tackle any corruption, better service delivery and contribute to better organizational performance (CIPFA \& IFAC, 2013). The public sector governance concerns with the accountability duties in relation to public goals and the impact of the policies on the community (Almquist, Grossi, Helden \& Reichard, 2012). The application of the corporate governance concept to various governmental departments and agencies in various countries is an excellent illustration (Howard \& Seth-Purdie, 2005). Therefore, such good governance needs to be given due consideration globally.

The needs of transparency and accountability have originated the idea of the term governance in any organization. Good governance displayed accountability, transparency, authority and responsibility structure and clear decision making within the public sector settings (Juiz, Guerrero \& Lera, 2014). According to Mukhtar and Ali (2011), quality governance initiatives are vital to guarantee that they are implemented successfully in order to achieve organizational goals. Also, good governance in been regarded as one key element that enables sustainable development and economic growth (Samsudin, 2011).

An environment where success can happen and be realized is produced through good governance (Fraser-Moleketi, 2007). Good corporate governance comprised of effective leadership (that established: organizational visions, clarity about strategy and objectives, roles and responsibilities), a culture based on honesty and openness, supporting accountability (through risk management and performance management) and finally, effective decision making (Wardman \& Koehler, 2003). Good governance within the public sector encourages the application of governance principles that may enable good decision making, strengthens the responsibility for the effective management of resources and ensure efficient utilization of resources (Juiz et al., 2014).

Conducting research on the application of good corporate governance within the public sector is an impression of the ways to improve the accountability and performance of such sector (Howard \& Seth-Purdie, 2005). It is important future research to study on the effect of governance framework in a different context (Williams et al., 2010). In the same vein, most of the previous studies on corporate governance and corporate performance were carried out within the private sector.

In Malaysia, continuous action has been taken to strengthen public sector governance practices in enhancing efficiency and improving the performance of the public sector service delivery system. Among them is the guideline on the practice of good governance that has been issued by the Chief Secretary to the Government (KSN) in March 2007, the circular PM (S) 17479/13 No. 4, 2007, entitled "Enhancing Corporate Governance for in Public Sector". The purpose of this guideline is to institutionalize the best governance principles and practices in the public sector in enhancing and strengthening its capabilities towards achieving the goals of the National Mission. 
Therefore, this study aims to provide some influence on the understanding of governance practices of public sector entities in Malaysia. The remainder of the paper is structured as follows. The next part reviews the governance in the public sector and governance best practices of the UK and Australian public sector. This is followed by a discussion of the methodology and results. The final part of the paper provides conclusions from the study.

\section{LITERATURE REVIEW}

\section{Governance in the Public Sector}

Public sector governance is bounded by various facets, including the management of an entity, corporate structures as well as other forms, culture, policies and strategies and the modus operandi of dealing with different stakeholders. The concept of corporate governance has a different kind of meanings in both the public and the private sector (Howard \& Seth-Purdie, 2005). Besides, Almquist et al., (2012), Samsudin (2011) and Williams et al., (2010) noted that governance is a term that has a different kind of meaning and usage and that different country has different models of corporate governance. The study concluded that public governance means formal and informal arrangements which determine how decisions are made within the public domain and how public actions are carried out which enhance the constitutional values of a country. This is in line with the OECD definition. Governance in the public sector means the ability to manage the economy; resources mobilization; the degree of social justice assurance; provision of enabling environment for individual goals achievement; and assurance of peace and security of the nation (Chowdhury \& Skarstedt, 2005). Generally, governance in the public or private sector means the act governing and good governance can be regarded as part of the development process.

CIPFA and IFAC (2014) defined governance in the public sector as "the arrangements put in place to ensure that the intended outcomes for stakeholders are defined and achieved". According to Juiz et al. (2014), corporate governance is defined as a mechanism which provides the environment for determining the achievement of organizational objectives and monitoring performance. According to Rhodes (1994), there are six different meanings of governance in the public sector, and one of them is governance as 'corporate governance', which refers to "the systems by which organizations are directed and controlled and has been used to identify fundamental principles such as openness, integrity and accountability that should underlie the activities of public sector bodies".

According to the Australian National Audit Office (2014), public sector governance refers to "the arrangements and practices which enable a public sector entity to set its direction and manage its operations to achieve expected outcomes and discharge its accountability obligations". It covers leadership, direction, control and accountability, and assists an entity to achieve its outcomes in order to enhance confidence in the entity, its decisions and its actions. Good public sector governance is about getting the right things done in the best possible way and delivering this standard of performance on a sustainable basis (ANAO, 2014). It includes management, guidance, control, and accountability, and helps an organization attain its results to improve trust in the organization, its choices, and actions. Good governance in the public sector is about doing the correct stuff in the best possible manner and on a sustainable basis in providing this standard of performance (ANAO, 2014).

Other than defining corporate governance, another important aspect to consider is the use of various terms that might generate confusion. Publications from the Institute of Internal Auditors (IIA) acknowledge the fact that the terms 'corporate governance', 'organizational governance' and 'governance' are used interchangeably to describe the same concept (Hermanson \& Rittenberg 2003; IIA 2006). The term 'organizational governance' (or governance) appears to be the most inclusive term, as it implies that the focus is on the governance of any organization and not only corporate/private or publicly listed companies.

The public sector is a complex sector which comprises of a multi-layered structure with specific characteristics and finalities. Spanhove and Verhoest (2007) stated that there are three level of public sector that can be distinguished as follows:

1. Macro level - where the whole administrative system with the government in charge of it.

2. Meso level - comprises of a policy sector with its constituent parts (department, departmental agencies, public law and private law agencies) headed by the minister and with a strategic policy committee.

3. Micro level - covers the single public sector organization/agency, headed by senior management and, in some cases, by a governing board.

This study focused on governance at the micro level, which also referred to as organizational governance of the government agencies at the federal level. It is also a level that gain more consideration in government administration due to various corruption cases involving an organization at this level.

\section{Governance Best Practices in United Kingdom Public Sector}

In the UK, the Committee on Standards in Public Life (the Nolan Committee) issued the report on corporate governance in the public services in 1995. This report, also known as Nolan Report, outlined seven general principles of good corporate governance comprising selflessness, integrity, objectivity, accountability, openness, honesty and leadership.

Later, the Chartered Institute of Public Finance and Accountancy (CIPFA) issued a public sector corporate governance framework through the combination of the principles from the Cadbury Report and the Nolan Report whereby it is regarded as one of the initial efforts on corporate governance in the UK public sector. This framework outlines the principles and standards of quality corporate governance that can be equally applied to all types of public services. The 
organizational structures and processes, financial reporting and internal controls, as well as standards of behaviour, are the three dimensions of corporate governance presented in this framework.

Eventually, the Independent Commission on Good Governance in Public Services was established by the Office for Public Management (OPM) and jointly worked with the Chartered Institute of Public Finance and Accountancy (CIPFA) aiming to develop a common code and set of principles for good governance across public services in the UK. The Commission commenced work in early 2004 involving two rounds of consultation with a wide range of stakeholders, through face-to-face discussions and meetings around the UK to produce the Good Governance Standard for Public Services. This standard comprises of six principles of good governance that are common to all public service organizations and to be utilized to assess good governance practices.

In order to revitalize better service delivery and improved accountability, CIPFA and International Federation of Accountants (IFAC) jointly published the International Framework: Good Governance in the Public Sector which can be used as a benchmark for aspects of good governance in the public sector in 2014. The development of this new international framework also appraised the principles drafted in the Good Governance Standard for Public Services. Based on the framework, governance includes the compositions set in place in ensuring the defined and achievement of intended outcomes for stakeholders. Ensuring that organizations always achieve their expected results while performing to the welfare of the general public and society is the ultimate task of good governance in the public sector.

The framework outlines seven principles in order to deliver good governance in the public sector. The first two principles, Principles A and B, are required for acting in the public interest in order to achieve their entity's objectives. Acting in the public interest implies primary consideration of the benefits for society, which should result in positive outcomes for service users and other stakeholders. The additional, effective arrangements for the five other principles (Principles $\mathrm{C}$ to $\mathrm{G}$ ) are required for achieving good governance in the public sector. The seven principles as stated in CIPFA and IFAC (2014) are as follows:

A. Behaving with integrity, demonstrating a strong commitment to ethical values, and respecting the rule of law.

B. Ensuring openness and comprehensive stakeholder engagement.

C. Defining outcomes in terms of sustainable economic, social, and environmental benefits.

D. Determining the interventions necessary to optimize the achievement of the intended outcomes.

E. Developing the entity's capacity, including the capability of its leadership and the individuals within it.

F. Managing risks and performance through robust internal control and strong public financial management.

G. Implementing good practices in transparency, reporting, and audit to deliver effective accountability.

\section{Governance Best Practices in Australian Public Sector}

Fundamental documents which advanced the perception of the meaning of public sector corporate governance in Australia include the ANAOs Applying Principles and Practice of Corporate Governance in Budget Funded Agencies (ANAO 1997) and Corporate Governance in Commonwealth Authorities and Companies (ANAO 1999). The ANAO framework has been paramount in the review of corporate governance frameworks in the Australian public sector. The ANAO's (2003) better practice guide on public sector governance is mainly to accommodate public sector organizations in Australia at improving their governance, as it furnished guidance on governance frameworks, concepts, protocols and procedures for public sector organizations as well as individuals to consider. This practice guide also intends to help the government officials working at all levels in Australian Public Service organizations to comprehend the main components of better governance further, as well as understanding the way to utilize them. Consequently, the guide is not targeted exclusively for individual worked at the pinnacle of organizations albeit the greater part of the matters brought up would be more related to them. The guide also allows aid for several organizations, particularly at state and local government level in Australia.

In 2014, the Australian National Audit Office assembled a new ANAO's 2014 Public Sector Governance Better Practice Guide to replace the ANAO's 2003 Public Sector Governance Better Practice Guide. The ANAO 2014's guide significantly reconsidered the substance that fortifies the key components which required for good governance and expands on them to deal with current governance matters and problems. This guide focuses more on the "importance of leadership, engaging beneficial stakeholder relationship, and working collaboratively across the entity, jurisdictional and sector boundaries to elevate policy outcomes". This guide also emphasizes the importance of a high performing public sector, especially in the light of fiscal constraints and public expectations for continuous augmentation towards public sector services as well as increasing the transparent processes and level of engagement with citizen and other stakeholders. The issuance of this guide is timely with the execution of the fundamental provision of the Public Governance, Performance and Accountability Act 2013 (PGPA Act) in 2014 - 2015. With the introduction of new governance perspectives and practices for public sector organizations, this guide also focuses on uplifting awareness towards enhancing more ascertained governance practices.

The ANAO 2014's guide outlines five principles for better practice of governance as follows:

1. Developing strong leadership at all levels of the entity, with a focus on ethical behaviour and continuous improvement.

2. Maintaining governance systems and processes that are fit for purpose.

3. Optimizing performance through planning, engaging with risk, innovation, and performance monitoring, evaluation and review. 
4. Focusing on openness, transparency and integrity, engaging constructively with stakeholders and promoting accountability through clear reporting on performance and operations.

5. Where appropriate, participating in collaborative partnerships to more effectively deliver programs and services, including partnerships outside government.

A. Table 1 below summarizes the comparison between the public sector governance framework in the UK/US and Australia.

Table 1: Comparison of International Public Sector Governance Framework

\begin{tabular}{|c|c|}
\hline $\begin{array}{c}\text { UK \& US } \\
\text { CIPFA (2014) } \\
\end{array}$ & $\begin{array}{c}\text { Australia } \\
\text { ANAO (2014) } \\
\end{array}$ \\
\hline $\begin{array}{l}\text { Behaving with integrity, demonstrating strong } \\
\text { commitment to ethical values, and respecting the rule of }\end{array}$ & $\begin{array}{l}\text { Developing strong leadership at all levels of the entity, } \\
\text { with a focus on ethical behaviour and continuous }\end{array}$ \\
\hline $\begin{array}{l}\text { Ensuring openness and comprehensive stakeholder } \\
\text { engagement. }\end{array}$ & $\begin{array}{l}\text { Maintaining governance systems and processes that are } \\
\text { fit for purpose (Policy and planning). }\end{array}$ \\
\hline $\begin{array}{l}\text { Defining outcomes in terms of sustainable economic, } \\
\text { social, and environmental benefits. }\end{array}$ & $\begin{array}{l}\text { Optimizing performance through planning, engaging } \\
\text { with risk, innovation, and performance monitoring, } \\
\text { evaluation and review (Performance Orientation). }\end{array}$ \\
\hline $\begin{array}{l}\text { Determining the interventions necessary to optimize the } \\
\text { achievement of the intended outcomes. }\end{array}$ & $\begin{array}{l}\text { Focusing on openness, transparency and integrity, } \\
\text { engaging constructively with stakeholders and promoting } \\
\text { accountability through clear reporting on performance } \\
\text { and operations (Openness, transparency and integrity). }\end{array}$ \\
\hline $\begin{array}{l}\text { Developing the entity's capacity, including the capability } \\
\text { of its leadership and the individuals within it. }\end{array}$ & $\begin{array}{l}\text { Where appropriate, participating in collaborative } \\
\text { partnerships to more effectively deliver programs and } \\
\text { services, including partnerships outside government } \\
\text { (Effective collaboration). }\end{array}$ \\
\hline $\begin{array}{l}\text { Managing risks and performance through robust internal } \\
\text { control and strong public financial management. } \\
\text { Implementing good practices in transparency, reporting, } \\
\text { and audit to deliver effective accountability. }\end{array}$ & \\
\hline
\end{tabular}

Source: CIPFA (2014) \& ANAO (2014)

\section{RESEARCH METHOD}

This study focuses on the evaluation of the international public sector governance best practices such as CIPFA (UK/US) and ANAO (Australia) in the Malaysian public sector entities. This study is based on a case study analysis of six public sector entities. There are three levels of government in the Malaysian public sector: Federal, state and local government. The federal government consists of ministries, departments and statutory bodies. There are 13 states in Malaysia, which consist of state government departments and statutory bodies. Local governments include city hall, city council, town council and district council that are governed under the state governments. For the purpose of assessing the governance best practices adoption by the public sector entities, this study focused on the federal statutory bodies only. The federal statutory bodies' annual reports were selected randomly, based on their availability on the internet. Federal statutory bodies are chosen due to the availability of the annual report as it is a mandatory requirement to prepare and publish their annual reports every year.

Qualitative research was carried out to address the research topic, using secondary data. The secondary sources are the selected public sector entities' annual reports and other related published data. All selected public sector entities are the federal statutory bodies which are required to publish their annual report based on the guidelines by Treasury Department of Malaysia. All the six selected case studies were examined using ten dimensions of governance, as shown in Table 2. 


\begin{tabular}{c} 
Dimension \\
\hline \hline Board of Directors \\
Audit Committee \\
Other Board of Directors' sub-committees \\
Values and Code of Ethics \\
Stakeholder relations \\
Risk management \\
Internal controls \\
Internal auditing \\
Integrity \\
Performance and evaluation \\
\hline
\end{tabular}

In terms of data analysis, qualitative document analysis was used to collect and assess the existing content of written documentation related to the study in order to extract pieces of information rigorously and systematically. Based on Creswell (2003) and Creswell and Plano Clark (2007), the archival data were analysed using a procedure known as content analysis.

\section{RESULTS}

This section elaborates on the results of the content analysis for the adoption of best governance practices by the public sector entities based on the six case studies of Federal statutory bodies in Malaysia.

According to the analysis of the case study, the compositions of the Board of Directors (BOD) in Malaysia public sector entities based on the six chosen entities are mostly mentioned in several annual reports. Most of the entities' composition consists of several ministry representatives and experienced members in the sectors. The frequencies of the BOD meetings are also disclosed in the annual reports of respective entities. The entities mostly disclose the qualifications and experiences of members of the boards. Nonetheless, most of the entities have only disclosed past experiences of the directors. The names and photos of the directors are also disclosed in the annual report as required by the Malaysian public sector governance practice. In CIPFA 2014 and ANAO 2014, there were no guidelines or regulations about the board of directors' meetings and compositions. However, CIPFA 2014 did mention about expanding the entity's capacity, including the capability of its leadership as well as the individuals within it. Explanations by CIPFA advises the public sector entities on the demands of proper arrangements and management, as well as people with the suitable competencies, pertinent qualifications and attitude, working productively and adequately to accomplish their planned results within the designated period. This can be said that the qualifications and the experiences of the directors are one of the factors that have been highlighted by CIPFA.

As for audit committee, the Malaysian public sector governance practice entails entities to disclose the frequency of the meetings, composition of members, qualification of members, functions or roles and photos with the names of the audit committee. The public sector entities also provided disclosure on the frequency of the meetings, composition of members, although without much depth and roles or functions of the audit committee. None of the entities provided disclosure on the qualification of members and the photos with the names of the committee members. In the CIPFA, things that should be disclosed were not mentioned in detail. Nevertheless, it stated that in order to intensify the effectiveness of an audit committee, the majority of its members should be independent members of the governing body. It is also important to note that the annual report of a public sector entity should comprise of appropriate information about the mandate, operations, activities, and outcomes of the audit committee to deliver effective accountability which means that the Malaysian public entities is in line with the UK Code in this dimension. On the other hand, ANAO also focused on optimizing performances through planning, risk engagement, innovation, as well as performance monitoring, evaluation and review which means that the audit and review of the planning and performance evaluation are required. It can be said that the Malaysian public entities are within the same pod as CIPFA and ANAO.

As for the other committees which are remuneration committee, nomination committee, procurement committee, risk committee, and Integrity and Governance Committee (JITU) that has been highlighted in the Malaysian public sector governance practice are established by the entity whereby the entities have also established more appropriate committees based on the sector of the entities respectively. As for the nomination committee and risk committee, only one of the six entities have established a committee for their entities. While CIPFA did not directly mention this committee, it did mention that building up the entity's capacity that is required for the public sector governing bodies is to ensure that their entities are in line and remain fit for purpose. This indicates to consider whether they continue to have the appropriate underlying governance and staffing structures to allow the delivery of planned services while ANAO mentions that the governance arrangements can be adjusted to meet the changing needs of the entities. This means that the entities can adjust to meet the most suitable structure while adapting to the changes. Almost all of the chosen entities have had their own additional committees to suit their sectors in order to increase the entities' capacity and corporate governance of the entity. 
Next, the Malaysian public sector governance practices emphasize about ethics and values. The same goes to CIPFA and ANAO as both provide emphasis on similar factors. In CIPFA, it has been stated that behaving with integrity, demonstrating a strong commitment to ethical values, and respecting the rule of law are some of the fundamental elements in their framework. It also stated that the members of the governing body should behave with integrity. Each governing body should nurture a culture where acting in the public interest at all times is the norm, along with a continual focus on achieving the entity's objectives. It is also giving an implementation idea known as feedback mechanisms. Other than that, CIPFA also emphasized on demonstrating strong commitment towards ethical values and respecting the rule of law including on the operational ways of the entity, the manner in which its core values are embedded such as by reflecting values in communications, processes, and behaviour as well as how it relates to its key stakeholders. As for ANAO, the emphasis was given on developing strong leadership at all levels of the entity, with a focus on ethical behaviour and continuous improvement. Thus, it is suggesting that entities should create a positive and ethical culture. To fulfill these procurements, it is important that leaders visibly set out the entity's core values, lay down the right tone and lead by example, make an active and clear commitment to sound public sector governance and a high performing entity as well as providing communication that is consistent together with appropriate messages both internally and externally to motivate good governance practice in the pursuit of a high level performance with accountability. Most of the entities disclosed their code of ethics, ethical culture, core value and shared values in their annual reports, which is also in accordance with the CIPFA and ANAO Code.

Next, Malaysian public sector governance practices accentuate on the internal control, which is the statement of internal control and a separate section on internal control. From the six chosen entities, only two disclosed statement of internal control and a separate section on internal control. Nonetheless, those entities did mention about their internal control. CIPFA emphasized on the internal control as it stated managing risks and performance through robust internal control and strong public financial management as it is one of the highlighted elements in the framework. Internal control supports a public sector entity in achieving its objectives by managing its risks while complying with rules, regulations, and organizational policies. Internal control is an integral part of an entity's governance system and risk management arrangements, which is understood, implemented, and actively monitored by the entity's governing body, management, and other personnel.

Furthermore, internal control should allow organizational goals to be achieved rather than obstructed. As for ANAO, one of the elements include optimizing performance through planning, engaging with risk, innovation, and performance monitoring, evaluation and review of performance orientation. The internal controls fall under the risk management process and practices.

Designed to add value and improve an organization's operations as well as helping an organization accomplish its objectives, internal auditing is an independent, intentional assurance and a consulting activity. Objectives are achieved by bringing a systematic, disciplined approach to evaluate and improve the effectiveness of risk management, control, and governance processes. Based on the analysis, most public entities in Malaysia disclosed internal audit in their annual report but provided only a little information such as the Chief of Internal Audit, his background, the function and responsibilities of the internal audit. Their function is to provide professional consultation and advisory services to the organization on the sufficiency, reliability as well as the effectiveness of the internal control system to ensure the appropriate regulations and procedure are adequate and complied with. Under ANAO, no guidelines or practices have been provided for effective governance through internal audit. This is similar to CIPFA, we acknowledge that the role of internal auditing is to provide independent, intentional assurance and consulting services modelled to help boost the value and enhance the activities of an entity. The internal audit activity enables an organization to achieve its goals through a systematic, disciplined approach to assessing and enhancing the effectiveness of governance, risk management, and control processes. Internal audit also yields reviews that can cover a broad variety of subjects, including those in relation to the value for money achievement and the fraud prevention and detection as well as corruption.

Public Entities in Malaysia have disclosed their risk framework in the annual report. They use MS ISO 31000:2010 Risk Management Principles and Guidelines and adopts a two-tier risk governance structure, which is institutional level based on the Three Lines of defence approach, supported by operational risk structure at divisional and branch levels. They also provide the functions of risk management in their practices which is to embrace risk management as an integral part of its decision-making process, operations and investment in ensuring effective risk management, and continuously promotes and inculcates sound risk management culture by adopting a strong risk governance structure and sound practices on risk management. This is similar to the third principle of the Australia's ANAO (2014) which highlighted the engagement of risk in optimizing the performance. Ultimately, the chief executive or board of directors are formally held responsible for risk management. All managers and staff are in control to manage risk, and strong ownership of risk identification as well as treatments will tend to execute better results. Under CIPFA, the practices provide the process to manage the risks, requiring a framework, managing, reviewing and engaged with the staff. Malaysian Practices are similar with both stated practices.

With the ethics and value in the entity, integrity within the entity might be increased. In Malaysia, Integrity Convention has been provided to foster awareness among staff on the needs and importance of building noble and integrity values. The involvement and support of heads of departments and top management in the Integrity Day programme can offer a good impression and builds the image of the organization towards enhancing a governance system that is sound and transparent. Other than that, it is appropriate to elaborate on issues related to disciplinary violations and to create awareness of good norms and behaviour among staff and to provide opportunity and space for staff to acquire and channel information concerning integrity issues expediently and accurately. Here, it will be shown that integrity is important and 
displays a strong commitment to ethical value in the organization. It is similar to CIPFA in terms of behaving with integrity, demonstrating a strong commitment to ethical value, and respecting the rule of law.

In CIPFA, integrity should be rendered in all governing body members. Each governing body should nurture a virtuous culture where acting in the public interest at all times is the norm, together with a continual focus on achieving the entity's objectives. These values should be communicated, understood, and shared. Malaysian Public Entities is also similar to both practices.

By providing links for complaints and inquiries, this will ease customers or any third party to make a complaint. Received complaint cases are serious and take a proper corrective and preventive action that is aimed at the root of the problems. Following CIPFA, complaints can shape a crucial part upon feedback and should be managed in efficient, effective, and in appropriate time in order for information obtained are utilized to refine the achievement of an organization and its functions in terms of both ethical and operational. A formal process, such as an ethics helpline, can be used to manage complaints. In addition, it can assist in identifying patterns upon forms of ethical misbehaviours, which later can be utilized to close the gaps in comprehending or in communicating the requirements and expectations. Under ANAO, no complaints section was provided under this code. Issues mentioned only included client feedback and complaints used to identify areas of deficiency or risk in facilities provided to the society.

According to the analysis in the public sector entities in Malaysia, most of them have a targeted and achieved Key Performance Indicators (KPI) as well as outcomes and impact of their entities. Everything has been disclosed in the annual report regarding the Key Performance Indicator using elements such as Balanced Scorecard, consisting of four key perspectives, namely Learning and Development, Internal Process, Finance and Customers and Stakeholders. The annual report also indicated the programs implemented such as Blood drive, meet the customer day and colouring contest, the agency or department that were involved, the outcomes as well as disclosure on the increase or decrease of the performance and also describing the reason of this performance. This is similar with Australia ANAO (2014) which focuses on openness, transparency and integrity, engaging constructively with stakeholders and promoting accountability through clear reporting on performance and operations (Openness, transparency and integrity). According to UK (CIPFA 2014), determining the interventions is necessary to optimize the achievement of the intended outcomes. This can be achieved by providing a mixture of legal, regulatory, and practical interventions to ensure that they achieve their intended outcomes.

\section{CONCLUSION}

This paper seeks to discover good governance practices in the public sector entities by assessing ten good governance dimensions following the international best governance practices guidelines. From the case studies analysis, it has been shown that the Federal statutory bodies in Malaysia are practising all the dimensions in the international public sector governance best practices. This implies that there are public sector entities that adopted the international best practices public sector governance, although it is not a mandatory requirement by the law. Though this paper provides some useful insights into governance practices among public sector entities, it is limited to case studies only on six federal statutory bodies and the non-financial information in the annual reports. This study might give more impact if primary data were used through focus group discussions and interviews with key governance players in the public sector. Expanding this research into other public sectors will also probably enhance the richness about the good governance practices in the Malaysian public sector.

\section{ACKNOWLEDGEMENT}

The authors would like to thank the Ministry of Education Malaysia for awarding the Exploratory Research Grant Scheme (ERGS-SO Code: 12171) to carry out this research project.

\section{REFERENCES}

Caccese, J. B., Buckley, T. A., Tierney, R. T., Arbogast, K. B., Rose, W. C., Glutting, J. J., \& Kaminski, T. W. (2018). Head and neck size and neck strength predict linear and rotational acceleration during purposeful soccer heading. Sports Biomechanics, 17(4), 462-476. https://doi.org/10.1080/14763141.2017.1360385

Huang, X., Sun, J., \& Sun, J. (2018). A car-following model considering asymmetric driving behavior based on long short-term memory neural networks. Transportation Research Part C: Emerging Technologies, 95(February), 346-362. https://doi.org/10.1016/j.trc.2018.07.022

James, S. L., Abate, D., Abate, K. H., Abay, S. M., Abbafati, C., Abbasi, N., Abbastabar, H., Abd-Allah, F., Abdela, J., Abdelalim, A., Abdollahpour, I., Abdulkader, R. S., Abebe, Z., Abera, S. F., Abil, O. Z., Abraha, H. N., Abu-Raddad, L. J., Abu-Rmeileh, N. M. E., Accrombessi, M. M. K., ... Murray, C. J. L. (2018). Global, regional, and national incidence, prevalence, and years lived with disability Almquist, R., Grossi, G., Helden, G. J., \& Reichard, C. (2012). Public sector governance and accountability. Critical Perspectives on Accounting, 24(7-8), 479-487. doi: 10.1016/j.cpa.2012.11.005

Australian National Audit Office (1999) Corporate Governance in Commonwealth Authorities and Companies, Discussion Paper.

Australian National Audit Office (ANAO) (1997). Applying Principles and Practice of Corporate Governance in Budget Funded Agencies, ANAO

Australian National Audit Office (ANAO) (2003). Better Practice Guide on Public Sector Governance.

Australian National Audit Office (ANAO) (2014). Better Practice Guide on Public Sector Governance.

Chartered Institute of Public Finance and Accountancy (1995) Corporate Governance: A Framework for Public Service Bodies, CIFPA, London. 
Chartered Institute of Public Finance and Accountancy (2011). CIPFA's submission to the EU on the Green Paper. The EU Corporate Governance Framework.

Chartered Institute of Public Finance and Accountancy (2014) Corporate Governance: A Framework for Public Service Bodies, CIFPA, London.

Chief Secretary Letter PM (S) 17479/13 No. 4, 2007, entitled "Enhancing Corporate Governance for in Public Sector".

Chowdhury, N., \& Skarstedt, C. E. (2005). The principle of good governance. Recent Developments in International Law Related to Sustainable Development.

CIPFA \& IFAC (2013). Good governance in the public sector - consultation draft for an international framework. Chartered Institute of Public Finance and Accountancy (CIPFA) and the International Federation of Accountants (IFAC).

CIPFA \& IFAC (2014). Good governance in the public sector - International framework. Chartered Institute of Public Finance and Accountancy (CIPFA) and the International Federation of Accountants (IFAC).

Cresswell, J. W. (2003). Research design: Qualitative, quantitative and mixed methods approaches (2nd ed.). California: Sage Publications.

Cresswell, J. W., \& Plano Clark, V. L. (2007). Designing and conducting mixed methods research. London: Sage Publication Inc.

Fraser-Moleketi, G. (2007). Towards a common understanding of corruption in Africa. International Journal of African Renaissance Studies, 2(2), 239-249. doi: 10.1080/18186870701751723

Hermanson, D. R., \& Rittenberg, L. E. (2003). Internal Audit and Organizational Governance. In Bailey, J. R., Gramling, A. A., \& Ramamoorti, S., EDS. 2003. Research Opportunities in Internal Auditing, Altamonte Springs, FL: The Institute of Internal Auditors.

Howard, C., \& Seth-Purdie1, R. (2005). Governance issues for public sector boards. Australian Journal of Public Administration, 64(3), 56-68. doi: 10.1111/j.1467-8500.2005.00452.x

IIA, (2006). The role of auditing in public sector governance. Institute of Internal Auditors.

International Federation of Accountants (IFAC) (2000). Corporate Governance in the Public Sector: A Governing Body Perspective.

International Federation of Accountants (IFAC) (2001). Governance in the public sector: A governing body perspective. International Public Sector Study. 535 Fifth Avenue, 26th Floor New York, New York 10017. United States of America.

Juiz, C., Guerrero, C., \& Lera, I. (2014). Implementing good governance principles for the public sector in information technology governance frameworks. Open Journal of Accounting, 3, 9-27. doi: 10.4236/ojacct.2014.31003

Mukhtar, R., \& Ali, N. A. (2011). Quality governance of human aspects of quality initiatives in the public service sector. Current Issues of Business and Law, 6, $111-128$.

Rhodes, R. A. W. (1994). The hollowing out of the state: The changing nature of the public service in Britain. The Political Quarterly, 65(2), 138-151. doi: 10.1111/j.1467-923X.1994.tb00441.x

Samsudin, S. (2011). A review of organizational arrangements in Malaysia land administration system towards good governance: Issues and challenges. Land Governance, paper 4853, 1- 15.

Spanhove, J., \& Verhoest, K. (2007). Analyzing Government Governance at different levels: Developing a normative and analytical framework based on principles, processes, instruments and cycles. Paper for the EGPA Seminar for Doctoral Students and Junior Researchers, Madrid, September 17-18.

Wardman, M., \& Koehler, I. (2003). Corporate governance: Improvement and trust in local public services. Public sector management paper.

Williams, T., Klakegg, O. J., Magnussen, O. M., \& Glasspool, H. (2010). An investigation of governance frameworks for public projects in Norway and the UK. International Journal of Project Management, 28, 40-50. doi: 10.1016/j.ijproman.2009.04.00 for 354 diseases and injuries for 195 countries and territories, 1990-2017: a systematic analysis for the Global Burden of Disease Study 2017. The Lancet, 392(10159), 1789-1858. https://doi.org/10.1016/S0140-6736(18)32279-7

Tan, H., Qin, L., Jiang, Z., Wu, Y., \& Ran, B. (2018). A hybrid deep learning based traffic flow prediction method and its understanding. Transportation Research Part C: Emerging Technologies, 90(January), 166-180. https://doi.org/10.1016/j.trc.2018.03.001

Taylor, K., Post, A., Hoshizaki, T. B., \& Gilchrist, M. D. (2019). The effect of a novel impact management strategy on maximum principal strain for reconstructions of American football concussive events. Proceedings of the Institution of Mechanical Engineers, Part P: Journal of Sports Engineering and Technology, 233(4), $503-513$. https://doi.org/10.1177/1754337119857434 